\title{
Does Calvo Meet Rotemberg at the Zero Lower Bound?*
}

\author{
Jianjun $\mathrm{Miao}^{\dagger} \quad$ Phuong V. Ngo
}

December 3, 2014

\begin{abstract}
This paper compares the Calvo model with the Rotemberg model in a fully nonlinear dynamic new Keynesian framework with an occasionally binding zero lower bound (ZLB) on nominal interest rates. Although the two models are equivalent to a first-order approximation, they generate very different results regarding the policy functions and the government spending multiplier based on nonlinear solutions. The multiplier in the Calvo model is less than one for low persistence of the government spending shock and rises above one as the persistence increases, but eventually decreases with the persistence and falls below one for sufficiently high persistence. In addition, the multiplier increases with the duration of the ZLB. By contrast, the multiplier in the Rotemberg model is less than one and decreases with the persistence. Surprisingly, it also decreases with the duration of the ZLB.
\end{abstract}

JEL classification: C61, E31, E52, E62.

Keywords: Calvo price adjustments, Rotemberg price adjustments, Taylor rule, ZLB, projection methods, dynamic new Keynesian models, government spending multiplier

*We thank Gauti Eggertsson, Lena Korber, and Taisuke Nakata for helpful conversations. We have benefitted from comments by John Leahy. First version: July 2014.

${ }^{\dagger}$ Department of Economics, Boston University, 270 Bay State Road, Boston, MA 02215, USA, CEMA, Central University of Finance and Economics, and AFR, Zhejiang University, China. Tel: +1 (617) 353 6675. Email: miaoj@bu.edu.

${ }^{\ddagger}$ Department of Economics, Cleveland State University, 2121 Euclid Avenue, Cleveland, OH 44115, USA. Tel: +1 (617) 347 2706. Email: p.ngo@csuohio.edu. 


\section{Introduction}

The recent experiences of Japan, the United States, and the Eurozone with (nearly) zero nominal interest rates have raised some important questions to macroeconomists: How does the economy behave when it faces a zero lower bound (ZLB) on nominal interest rates? What is the impact of monetary and fiscal policies on the economy when the ZLB binds occasionally? What is the optimal monetary policy? To address these questions, researchers typically adopt the dynamic new Keynesian (DNK) framework with the price setting mechanism as one of its most important building blocks (Woodford (2003) and Gali (2008)).

The two most popular modeling approaches to price setting used in the ZLB literature are due to Calvo (1983) and Rotemberg (1982). According to the Calvo approach, firms face an exogenously fixed probability of adjusting their prices each period, while, according to the Rotemberg approach, firms pay quadratic adjustment costs to adjust their prices. It is well known that the two approaches are equivalent up to a first-order approximation in the absence of the ZLB. However, whether or not these two approaches generate the same results in a fully nonlinear dynamic stochastic general equilibrium (DSGE) framework with occasionally binding ZLB is not well understood. Understanding this issue is important not only for academic researchers but also for policymakers because one may provide different answers to the questions raised above and draw different policy implications if the two approaches generate very different results.

The goal of our paper is to compare the quantitative predictions of the Calvo model and the Rotemberg model in the presence of the ZLB on nominal interest rates using a global nonlinear numerical method. For computational tractability, we consider a simple setup without capital and with two $\operatorname{AR}(1)$ shocks. The first is a preference shock to the household discount factor, which is a simple way to force the economy to enter the ZLB. The second is a shock to government spending used for us to understand the government spending multiplier. We focus on the following specific questions: (1) Do the two models generate the same policy functions and business cycle dynamics? (2) Is the government spending multiplier the same in the two models during normal times when the ZLB is not binding and during deep recessions when the ZLB binds? If not, how different are they? (3) What is the impact of the persistence of the government spending shock on the multiplier?

Based on a conventional calibration, we find the following main results. First, under a positive preference shock driving the economy close to a liquidity trap, the interest rate cut is greater in the Calvo model than in the Rotemberg model. Thus the ZLB is more likely to bind 
and the recession is more severe in the Calvo model than in the Rotemberg model. Second, the government spending multiplier is smaller than one on impact in the Rotemberg model even when the ZLB binds. Finally, while the government spending multiplier is also smaller than one on impact in the Calvo model when the ZLB does not bind, it is greater than one (around 1.18) when the ZLB binds.

To understand the differences in results for the two models, we have to understand the nature of the price rigidities underlying these models. The Calvo model produces a price dispersion term, which generates a wedge between output and hours and acts as a negative technology shock. This term is backward looking and is a state variable. By contrast, the Rotemberg model assumes a quadratic cost of adjusting prices, which generates a wedge between output and (private and public) consumption. In this model the relative price dispersion is always equal to one. If the steady state inflation rate is zero, these two wedges vanish and the two models are equivalent up to a first order approximation. In fully nonlinear solutions when the ZLB binds, the relative price dispersion can be substantially greater than one in the Calvo model, generating a large output loss and substantially different results from those in the Rotemberg model.

Specifically, when the ZLB binds, the central bank is unable to reduce the nominal interest rate to achieve an inflation rate that is close to the zero inflation target. Following a positive discount factor shock that pushes the ZLB to bind, there is a sharp decline in output and large deflation, resulting in a substantial increase in the relative price dispersion in the Calvo model. This increase in the relative price dispersion causes output to fall even more, amplifying the impact of the shock. On top of the preference shock, a positive government spending shock raises aggregate demand and inflation (or reduces deflation). When the ZLB binds, the real interest rate falls, causing consumption to rise due to the substitution effect. Thus output rises more than government spending, generating a larger-than-one multiplier in the Calvo model.

By contrast, the quadratic adjustment costs in the Rotemberg model absorb some resources (total output). In response to a government spending shock, deflation is reduced on impact, causing the adjustment costs to fall. This fall offsets the rise in consumption, generating a smaller-than-one multiplier in the Rotemberg model.

We then vary the persistence parameter of the government spending shock and find the following important and surprising result: The government spending multiplier is always less than one and decreases with the persistence in the Rotemberg model, but it is hump-shaped in the Calvo model. The multiplier in the Calvo model is less than one when the persistence is sufficiently small or sufficiently large. To understand the intuition, we consider two extremes. 
In one extreme, when the government spending shock is purely temporary, deflation is reduced on impact so that inflation is closer to the target of zero. The relative price dispersion falls on impact. Since it is a state variable in the Calvo model, it gradually rises to the level associated with the preference shock alone even though there is no government spending shock after the impact period. Since the relative price dispersion acts as a negative technology shock, the smaller relative price dispersion has a positive supply effect, causing more deflation when there is no government spending shock after the impact period. As a result, the real interest rate rises due to the binding $\mathrm{ZLB}$, leading to a fall in consumption on impact so that the multiplier is less than one for a purely temporary government spending shock in the Calvo model. By contrast, the relative price dispersion is not a state variable in the Rotemberg model. Inflation rises (deflation falls) on impact and then returns to the level with the preference shock alone immediately after the impact period. Consumption stays unchanged because the real interest rate does not change by the Fisher relation. But the multiplier is the largest and still less than one because the fall in quadratic adjustment costs is the smallest.

In the other extreme, when the government spending shock is very persistent (say the persistent parameter is equal to 0.9), the negative wealth effect is large because households must pay taxes to finance large government spending. This negative effect can dominate the positive substitution effect so that consumption falls in both the Calvo and Rotemberg models. Thus the multiplier is less than one when persistence is sufficiently large in the Calvo model. It is less than one and decreases monotonically with persistence in the Rotemberg model.

It is often believed that the government spending multiplier is larger when the duration of the ZLB is longer because the real interest rate can stay low for a longer time. We show that this view is correct for the Calvo model, but does not hold true for the Rotemberg model. When the duration of the ZLB is longer, deflation is smaller and the fall in adjustment costs is larger in response to a government spending shock, causing the multiplier to be smaller. Note that this result is not due to the possibility that the economy may escape from the ZLB since the government spending shock is very small in our experiments.

We emphasize that the conventional Rotemberg model typically assumes that adjustment costs are a part of aggregate demand (waste of resources). To see the importance of this modeling, we consider an alternative model in which adjustment costs are rebated back to households so that output is equal to the sum of private consumption and government spending. In this case the negative wealth effect of an increase in government spending is mitigated. As a result, the government spending multiplier is always larger than one and has a hump-shaped relation with the persistence parameter of the government spending shock. 


\section{Related literature}

In the existing literature on the government spending multiplier under the ZLB, many researchers use the log-linearized version of the fully nonlinear models presented in this paper (e.g., Eggertsson (2011), Christiano et al. (2011), Eggertsson and Krugman (2012), and Woodford (2011)). Following Eggertsson and Woodford (2003), many researchers adopt a two-state Markov shock with the zero steady-state inflation being an absorbing state. This shock pushes the economy to the ZLB. The subsequent exit from the ZLB is exogenous and occurs with a given fixed probability. As is well known, the (log-)linear approximation method is based on local approximations and is highly inaccurate when shocks are sufficiently large or when there is a kink in the model with a ZLB constraint. Our results based on global nonlinear solutions suggest that one has to be cautious to use log-linearized solutions for policy analysis in the presence of the ZLB.

Christiano et al. (2011) and Woodford (2011) discuss the impact of the timing and duration of government spending. They show that when the fiscal stimulus lasts longer than the duration of the ZLB, it will have a negative effect on the fiscal multiplier. Since they consider a two-state Markov shock that pushes the economy to the ZLB, they can analyze the impact of the different paths of government spending within the ZLB and outside the ZLB. In our model, the driving shock to enter the ZLB is $\mathrm{AR}(1)$ and it is a purely random event when the economy enters the ZLB. We thus specify an AR(1) process for the government spending shock as in the DSGE literature. The impact of the persistence of this shock is related to the effect of the timing and duration of government spending discussed by Christiano et al. (2011) and Woodford (2011).

It is widely believed that DNK models with sticky prices typically generate a larger-thanone government spending multiplier when the ZLB binds. The intuition is that government spending can generate higher inflation (or lower deflation) that in turn lowers the real interest rate, promoting consumption, investment, and output. It is worth noting that this view is typically based on models with either Calvo or Rotemberg pricing. Our paper shows that the conventional view is very sensitive to the persistence of the government spending shock and numerical solution methods. As a result, the conclusion that the government spending multiplier is typically greater than one when the ZLB binds in DNK models needs qualification.

We now discuss other papers in the related literature. Following the seminal contributions by Krugman (1998) and Eggertsson and Woodford (2003), there is a growing literature studying the consequences of the ZLB. ${ }^{1}$ Braun et al. (2013) use a global method to solve a DNK model

\footnotetext{
${ }^{1}$ In addition to the papers cited in the main text, an incomplete list includes Adam and Billi (2006, 2007) and Mertens and Ravn (2014).
} 
with Rotemberg pricing. They consider a two-state Markov shock with the zero steady-state inflation being an absorbing state as in Eggertsson and Woodford (2003). They find that the government spending multiplier is about one or less for a large set of empirically relevant parameter values. Braun and Waki (2010) compare the Calvo and Rotemberg models using a nonlinear shooting method in a deterministic perfect foresight framework. They also compare their nonlinear solution with the log-linearized solution. Aruoba and Shorfheide (2013) estimate a DNK model with Rotemberg pricing. As Benhabib et al. (2001, 2002) point out, there exist multiple equilibria in the presence of the ZLB. Aruoba and Shorfheide (2013) use nonlinear numerical methods to solve the standard targeted inflation equilibrium, a deflation equilibrium as well as a Markov sunspot equilibrium that switches between a targeted-inflation and a deflation regime. ${ }^{2}$ They find a case where the government spending multiplier is less than one. Unlike their paper, but like Fernandez-Villaverde et al. (2012), we focus on the targeted inflation equilibrium only.

In terms of solution methods, our paper is most closely related to the papers by Judd et al. (2011), Fernandez-Villaverde et al. (2012), Gust et al. (2012), and Aruoba and Shorfheide (2013). All these papers use global projection methods to approximate agents' decision rules in a DNK model with a ZLB constraint. ${ }^{3}$ But some details of the implementation of the solution algorithm are different. In particular, Gust et al. (2012) use Bayesian methods to estimate a nonlinear DNK model with Rotemberg pricing. Here we follow Ngo (2014) and use the cubic splines to approximate policy functions and use the collocation method to implement the projection method. Our methods and analysis are similar to those in Fernandez-Villaverde et al. (2012). Unlike ours, that paper does not study the impact of the persistence of the government spending shock and does not compare with the Rotemberg model.

Our paper is also related to the work by Ascari and Rossi (2012) who compare the Calvo and Rotemberg models without a ZLB constraint. They use log-linear approximations to show that the Calvo and Rotemberg models imply very different results when the models are approximated at a positive steady state inflation rate. Our analysis is different from theirs. We show that even though the two models with a ZLB constraint imply the same results to a first-order approximation around the zero steady-state inflation rate, they deliver very different results in global nonlinear solutions at the ZLB.

The remainder of this paper is organized as follows. Section 2 presents models. Section

\footnotetext{
${ }^{2}$ At the targeted inflation equilibrium, the economy fluctuates around the steady state where the ZLB does not bind and actual inflation coincides with the cental bank's inflation target. At the deflation equilibrium, the ZLB binds in the steady state.

${ }^{3}$ Except for Aruoba and Shorfheide (2013), these papers solve the targeted inflation equilibrium only.
} 
3 discusses a benchmark calibration and solution methods. Section 4 provides results. Section 5 contains some sensitivity analyses of the main findings with respect to some important assumptions. Section 6 concludes.

\section{Models}

We present two otherwise identical DNK models with different pricing mechanisms. Both models consist of a continuum of identical households, a continuum of identical competitive final good producers, a continuum of monopolistically competitive intermediate goods producers, and a government (monetary and fiscal authorities).

\subsection{Households}

The representative household maximizes his expected discounted utility

$$
E\left\{\sum_{t=0}^{\infty} \beta^{t} \Theta_{t}\left(\frac{C_{t}^{1-\gamma}}{1-\gamma}+\chi \frac{N_{t}^{1+\eta}}{1+\eta}\right)\right\}
$$

subject to the budget constraint

$$
P_{t} C_{t}+\left(1+i_{t}\right)^{-1} B_{t}=W_{t} N_{t}+B_{t-1}+\Pi_{t}+T_{t}
$$

where $C_{t}$ is consumption, $i_{t}$ is the nominal interest rate, $B_{t}$ denotes one-period bond holdings, $N_{t}$ is labor, $W_{t}$ is the nominal wage rate, $\Pi_{t}$ is the profit income, $T_{t}$ is the lump-sum tax, and $\Theta_{t}$ denotes the preference shock to the subjective discount factor $\beta \in(0,1)$. Define $\beta_{t}=\Theta_{t+1} / \Theta_{t}$, $\Theta_{0}=1$, and assume that $\beta_{t}$ follows an $\operatorname{AR}(1)$ process

$$
\ln \left(\beta_{t+1}\right)=\rho_{\beta} \ln \left(\beta_{t}\right)+\varepsilon_{\beta, t+1}, \beta_{0}=1,
$$

where $\rho_{\beta} \in(0,1)$ is the persistence of the preference shock and $\varepsilon_{\beta t}$ is the innovation of the

preference shock with mean 0 and variance $\sigma_{\beta}^{2}$. The preference shock is a reduced form of more realistic forces that can drive the nominal interest rate to the ZLB.

The first-order conditions for the household optimization problem are given by

$$
\chi N_{t}^{\eta} C_{t}^{\gamma}=w_{t}
$$

and

$$
E_{t}\left[M_{t, t+1}\left(\frac{1+i_{t}}{1+\pi_{t+1}}\right)\right]=1
$$

where $w_{t}=W_{t} / P_{t}$ is the real wage, $\pi_{t}=P_{t} / P_{t-1}-1$ is the inflation rate, and the stochastic discount factor is given by

$$
M_{t, t+1}=\beta \beta_{t}\left(\frac{C_{t+1}}{C_{t}}\right)^{-\gamma}
$$




\section{$2.2 \quad$ Final good producers}

To produce the final good, the final good producers buy and aggregate a variety of intermediate goods indexed by $i \in[0,1]$ using a CES technology

$$
Y_{t}=\left(\int_{0}^{1} Y_{t}(i)^{\frac{\epsilon-1}{\epsilon}} d i\right)^{\frac{\epsilon}{\epsilon-1}},
$$

where $\varepsilon$ is the elasticity of substitution among intermediate goods. The profit maximization problem is given by

$$
\max P_{t} Y_{t}-\int_{0}^{1} P_{t}(i) Y_{t}(i) d i
$$

where $P_{t}(i)$ and $Y_{t}(i)$ are the price and quantity of intermediate good $i$. Profit maximization and the zero-profit condition give the demand for intermediate good $i$

$$
Y_{t}(i)=\left(\frac{P_{t}(i)}{P_{t}}\right)^{-\epsilon} Y_{t}
$$

and the aggregate price level

$$
P_{t}=\left(\int P_{t}(i)^{1-\epsilon} d i\right)^{\frac{1}{1-\epsilon}}
$$

\subsection{Intermediate goods producers}

There is a unit mass of intermediate goods producers on $[0,1]$ that are monopolistic competitors. Suppose that each intermediate good $i \in[0,1]$ is produced by one producer using the linear technology

$$
Y_{t}(i)=A_{t} N_{t}(i)
$$

where labor is the only input and $A_{t}$ denotes aggregate productivity. Assume that $A_{t}$ follows an $\operatorname{AR}(1)$ process

$$
\ln A_{t}=\rho_{A} \ln A_{t-1}+\varepsilon_{A t},
$$

where $\rho_{A} \in(0,1)$ is the persistence parameter and $\varepsilon_{A t}$ is the innovation with mean 0 and variance $\sigma_{A}^{2}$. Cost minimization implies that each firm faces the same real marginal cost

$$
m c_{t}=m c_{t}(i)=\frac{w_{t}}{A_{t}} .
$$

\subsection{Price setting mechanisms}

Intermediate good producers have market power and set prices to maximize discounted profits. They face frictions to adjust prices and thus price adjustments are sticky. We follow Calvo (1983) and Rotemberg (1982) to model sticky prices. 


\subsubsection{The Calvo model}

According to Calvo (1983), in each period an intermediate goods firm $i$ keeps its previous price with probability $\theta$ and resets its price with probability $(1-\theta)$. The price setting problem is given by

$$
\max _{P_{t}(i)} E_{t} \sum_{j=0}^{\infty}\left\{\theta^{j} M_{t, t+j}\left[\frac{P_{t}(i)}{P_{t+j}}-m c_{t+j}\right] Y_{t+j}(i)\right\}
$$

subject to its demand in equation (7) and

$$
M_{t, t+j}=1 \text { if } j=0, M_{t, t+j}=\prod_{s=0}^{j-1} M_{t+s, t+s+1} \text { for } j \geq 1 .
$$

The optimal relative price, $p_{t}^{*}=P_{t}^{*}(i) / P_{t}$, is the same for all firms who have a chance to reset their prices today and is given by

$$
p_{t}^{*}=\frac{P_{t}^{*}(i)}{P_{t}}=\frac{\varepsilon}{\varepsilon-1} \frac{E_{t} \sum_{j=0}^{\infty}\left\{\theta^{j} M_{t, t+j}\left(\frac{P_{t+j}}{P_{t}}\right)^{\varepsilon} Y_{t+j} m c_{t+j}\right\}}{E_{t} \sum_{j=0}^{\infty}\left\{\theta^{j} M_{t, t+j}\left(\frac{P_{t+j}}{P_{t}}\right)^{\varepsilon-1} Y_{t+j}\right\}} .
$$

After some manipulation, we can rewrite the optimal pricing rule as

$$
p_{t}^{*}=\frac{S_{t}}{F_{t}},
$$

where $S_{t}$ and $F_{t}$ satisfy the following recursive equations:

$$
\begin{gathered}
S_{t}=\frac{\varepsilon}{\varepsilon-1} C_{t}^{-\gamma} Y_{t} \frac{w_{t}}{A_{t}}+\theta \beta E_{t}\left[\beta_{t}\left(1+\pi_{t+1}\right)^{\varepsilon} S_{t+1}\right], \\
F_{t}=C_{t}^{-\gamma} Y_{t}+\theta \beta E_{t}\left[\beta_{t}\left(1+\pi_{t+1}\right)^{\varepsilon-1} F_{t+1}\right] .
\end{gathered}
$$

\subsubsection{The Rotemberg model}

Rotemberg (1982) assumes that each intermediate goods firm $i$ faces costs of adjusting prices, which are measured in terms of the final good and given by

$$
\frac{\varphi}{2}\left(\frac{P_{t}(i)}{P_{t-1}(i)}-1\right)^{2} Y_{t}
$$

where $\varphi$ is the adjustment cost parameter which determines the degree of nominal price rigidity. The problem of firm $i$ is given by

$$
\max _{\left\{P_{i, t}\right\}} E_{t} \sum_{j=0}^{\infty}\left\{M_{t, t+j}\left[\left(\frac{P_{t+j}(i)}{P_{t+j}}-m c_{t}\right) Y_{t+j}(i)-\frac{\varphi}{2}\left(\frac{P_{t+j}(i)}{P_{t+j-1}(i)}-1\right)^{2} Y_{t+j}\right]\right\}
$$


subject to its demand in equation (7), where $M_{t, t+j}$ is the stochastic discount factor defined in equation (6).

In a symmetric equilibrium, all firms will choose the same price and produce the same quantity, i.e., $P_{t}(i)=P_{t}$ and $Y_{t}(i)=Y_{t}$. The optimal pricing rule then implies that

$$
\left(1-\varepsilon+\varepsilon \frac{w_{t}}{A_{t}}-\varphi \pi_{t}\left(1+\pi_{t}\right)\right) Y_{t}+\varphi E_{t}\left[M_{t, t+1} \pi_{t+1}\left(1+\pi_{t+1}\right) Y_{t+1}\right]=0 .
$$

\subsection{Monetary and fiscal policies}

The central bank conducts monetary policy using a simple Taylor rule as follows:

$$
\begin{aligned}
\frac{1+i_{t}}{1+i} & =\left(\frac{G D P_{t}}{G D P}\right)^{\phi_{y}}\left(\frac{1+\pi_{t}}{1+\pi}\right)^{\phi_{\pi}}, \\
i_{t} & \geq 0
\end{aligned}
$$

where $G D P_{t} \equiv C_{t}+G_{t}$ denotes the gross domestic product (GDP) and $G D P, \pi$, and $i$ denote the steady state GDP level, the targeted inflation rate, and the steady-state nominal interest rate, respectively. ${ }^{4}$ As Braun et al. (2013) point out, in the Rotemberg model the distinction between GDP and output $Y_{t}$ matters in the presence of ZLB due to the pricing adjustment costs. Equation (19) implies that the nominal interest rate is not allowed to be negative. This is the key condition in the ZLB literature.

Following Fernandez-Villaverde et al. (2012), Braun et al. (2013), and Aruoba and Shorfheide (2013), we assume that the government runs a balanced budget and raises lump-sum taxes to finance government spending, which is given by

$$
G_{t}=Y_{t}\left(S_{g} g_{t}\right)
$$

where $S_{g}$ denotes the steady state share of the government spending and $g_{t}$ denotes the government spending shock that follows an $\operatorname{AR}(1)$ process

$$
\ln g_{t}=\rho_{g} \ln g_{t-1}+\varepsilon_{g t},
$$

where $\rho_{g} \in(0,1)$ is the persistence parameter and $\varepsilon_{g t}$ is the innovation with mean 0 and variance $\sigma_{g}^{2}$.

\footnotetext{
${ }^{4}$ Some researchers use the flexible price equilibrium output as the output target in the Taylor rule and some researchers also include the lagged interest rate. These alternative specifications will not change our key insights.
} 


\subsection{Equilibrium systems}

In the Calvo model we define aggregate labor as $N_{t}=\int N_{t}(i) d i$. By equations (7) and (9),

$$
N_{t}(i)=\frac{1}{A_{t}}\left(\frac{P_{t}(i)}{P_{t}}\right)^{-\epsilon} Y_{t}
$$

This implies that aggregate output is given by

$$
Y_{t}=\frac{A_{t} N_{t}}{\Delta_{t}}
$$

where $\Delta_{t}$ is called the relative price dispersion and is defined as

$$
\Delta_{t}=\int\left(\frac{P_{t}(i)}{P_{t}}\right)^{-\varepsilon} d i
$$

Equation (20) shows that the relative price dispersion $\Delta_{t}$ acts as a negative technology shock. An increase in the relative price dispersion reduces aggregate output.

By $(21), \Delta_{t}$ satisfies the recursive equation

$$
\Delta_{t}=\theta \Pi_{t}^{\varepsilon} \Delta_{t-1}+(1-\theta)\left(p_{t}^{*}\right)^{-\varepsilon}
$$

By (8),

$$
p_{t}^{*}=\left(\frac{1-\theta \Pi_{t}^{\varepsilon-1}}{1-\theta}\right)^{\frac{1}{1-\varepsilon}} .
$$

Combining these two equations yields

$$
\Delta_{t}=(1-\theta)\left(\frac{1-\theta \Pi_{t}^{\varepsilon-1}}{1-\theta}\right)^{\frac{\varepsilon}{\varepsilon-1}}+\theta \Pi_{t}^{\varepsilon} \Delta_{t-1} .
$$

The resource constraint for the Calvo model is given by

$$
C_{t}+G_{t}=Y_{t}
$$

The equilibrium system for the Calvo model consists of a system of ten nonlinear difference equations (4), (5), (13), (14), (15), (18), (20), (23), (24) (25) together with the ZLB (19) for ten variables $w_{t}, C_{t}, p_{t}^{*}, S_{t}, F_{t}, i_{t}, N_{t}, \pi_{t}, \Delta_{t}$, and $Y_{t}$.

In the Rotemberg model the relative price dispersion is always equal to one. Aggregate output satisfies

$$
Y_{t}=A_{t} N_{t}
$$

and the resource constraint is given by

$$
C_{t}+G_{t}+\frac{\varphi}{2} \pi_{t}^{2} Y_{t}=Y_{t}
$$


The equilibrium system for the Rotemberg model consists of a system of six nonlinear difference equations (4), (5), (17), (18), (26), (27) together with the ZLB (19) for six variables $w_{t}, C_{t}, i_{t}$, $\pi_{t}, N_{t}$, and $Y_{t}$.

\subsection{Log-linearized solutions}

By a standard procedure (e.g., Woodford (2003), Gali (2008), and Miao (2014)), we can derive the log-linearized approximations around the non-stochastic steady state with zero inflation. We omit the detailed derivations and present the solutions directly. The log-linearized system for the Calvo model is given by

$$
\begin{aligned}
i_{t} & =\max \left\{0, \phi_{y} x_{t}+\phi_{\pi} \pi_{t}+\ln (1 / \beta)+\phi_{y} \ln \left(Y_{t}^{f}\right)\right\} \\
x_{t} & =E_{t} x_{t+1}-\frac{1}{\gamma}\left(i_{t}-E_{t} \pi_{t+1}\right)+\frac{1}{\gamma} r_{t}^{n}, \\
\pi_{t} & =\beta E_{t} \pi_{t+1}+\kappa x_{t},
\end{aligned}
$$

where $\kappa$ is defined as

$$
\kappa=\frac{(\gamma+\eta)(1-\theta)(1-\theta \beta)}{\theta}
$$

$Y_{t}^{f}$ is the flexible price equilibrium output,

$$
Y_{t}^{f}=\left(\frac{\varepsilon-1}{\varepsilon \chi} \frac{A_{t}^{\eta+1}}{\left(1-S_{g} g_{t}\right)^{\gamma}}\right)^{\frac{1}{\eta+\gamma}}
$$

$x_{t}=\ln Y_{t}-\ln Y_{t}^{f}$ denotes the output gap, and $r_{t}^{n}$ is the real natural rate of interest,

$$
r_{t}^{n}=-\ln \beta-\ln \beta_{t}-\frac{\gamma(1+\eta)}{\eta+\gamma}\left(1-\rho_{A}\right) \ln A_{t}+\frac{\gamma \eta}{\eta+\gamma} \frac{S_{g}}{1-S_{g}}\left(1-\rho_{g}\right) \ln g_{t} .
$$

The log-linearized system for the Rotemberg model is given by

$$
\begin{aligned}
i_{t} & =\max \left\{0, \phi_{y} x_{t}+\phi_{\pi} \pi_{t}+\ln (1 / \beta)+\phi_{y} \ln \left(Y_{t}^{f}\right)\right\} \\
x_{t} & =E_{t} x_{t+1}-\frac{1}{\gamma}\left(i_{t}-E_{t} \pi_{t+1}\right)+\frac{1}{\gamma} r_{t}^{n} \\
\pi_{t} & =\beta E_{t} \pi_{t+1}+\widetilde{\kappa} x_{t}
\end{aligned}
$$

where $\widetilde{\kappa}$ is given by

$$
\widetilde{\kappa}=\frac{(\gamma+\eta)(\varepsilon-1)}{\varphi} .
$$

From the equations above, we deduce that by choosing the price adjustment cost parameter $\varphi=(\varepsilon-1) \theta /[(1-\theta)(1-\theta \beta)]$, we have $\kappa=\widetilde{\kappa}$ and the two models give the same equilibrium system to the first-order approximation. Therefore, results from the two models are the same 
even in the presence of the ZLB. We emphasize that this result holds true only when we approximate around the zero steady-state inflation rate. Ascari and Rossi (2012) show that the two models imply different results to the first-order approximation when the approximation is around a positive steady-state inflation rate.

\section{Nonlinear solution method and calibration}

\subsection{Solution method}

We use the projection method described in Judd (1998) to numerically solve the policy functions for the targeted inflation equilibrium (see footnote 2) in both the Calvo model and the Rotemberg model. The detailed algorithm is similar to that in Ngo (2014). Here we only describe the key idea. We use the collocation method to implement the project method and use cubic splines to approximate policy functions to capture kinks due to the ZLB. At each collocation node we solve a complementarity problem using the Newton method and the semi-smooth root-finding algorithm as described in Miranda and Fackler (2002). We also use an analytical Jacobian matrix computed from the approximating functions. Moreover, we write our code using a parallel computing method that allows us to split up a large number of collocation nodes into smaller groups assigned to different processors to be solved simultaneously. This procedure reduces computation time significantly. We obtain the maximal absolute residual across the equilibrium conditions of the order of $10^{-8}$ for almost all states off the collocation nodes. For a few states when the ZLB becomes binding, the maximal absolute residual is of the order of $10^{-5}$.

\subsection{Calibration}

We calibrate the parameters on the basis of the observed data and other studies. The quarterly subjective discount factor $\beta$ is set at 0.99, as in Woodford (2003), Gali (2008) and Christiano et al. (2011). The constant relative risk aversion parameter $\gamma$ is 1 , corresponding to a log utility function with respect to consumption. This utility function is commonly used in the literature of business cycles. The labor supply elasticity with respect to wages is set at 1 , or $\eta=1$, as in Christiano et al. (2011). We set $\chi=1$. The elasticity of substitution among differentiated intermediate goods $\epsilon$ is 7.66 , corresponding to a $15 \%$ net markup that is in the range found by Diewert and Fox (2008). This value is also popular in the literature (e.g., Adam and Billi (2007) and Braun et al. (2013)).

The probability of keeping prices unchanged in the Calvo model is calibrated to be $\theta=0.75$, 
Table 1: Calibration

\begin{tabular}{lll}
\hline Symbol & & \multicolumn{1}{c}{ Description } \\
\hline$\beta$ & Quarterly discount factor & 0.99 \\
$\gamma$ & CRRA parameter & 1 \\
$\eta$ & Inverse labor supply elasticity & 1 \\
$\varepsilon$ & Monopoly power & 7.66 \\
$\theta$ & Probability of keeping prices unchanged in the Calvo model & 0.75 \\
$\varphi$ & Price adjustment cost parameter in the Rotemberg model & 78 \\
$\pi$ & Inflation target & 0 \\
$\phi_{\pi}$ & Weight of inflation target in the Taylor rule & 1.5 \\
$\phi_{y}$ & Weight of output target in the Taylor rule & 0.125 \\
$S_{g}$ & Share of the government spending at the steady state & 0.2 \\
$\sigma_{\beta}$ & Standard deviation of the innovation of preference shocks $(\%)$ & 0.15 \\
$\rho_{\beta}$ & AR-coefficient of preference shocks & 0.8 \\
$\sigma_{g}$ & Standard deviation of the innovation of government spending shocks $(\%)$ & 0.25 \\
$\rho_{g}$ & AR-coefficient of government spending shocks & 0.8 \\
\hline
\end{tabular}

resulting in the average duration of four quarters with prices being kept unchanged. The price stickiness parameter is in line with the empirical evidence reported by Nakamura and Steinsson (2008). We then set the price adjustment cost parameter in the Rotemberg model $\varphi=78$ to ensure that the two models are equivalent to the first-order approximation around the steady state with zero inflation. This value also implies that the average duration of keeping prices unchanged is four quarters, as in the Calvo model.

The inflation target is set at zero. We choose this value to make sure that, together with $\theta=0.75$ and $\varphi=78$, the Calvo model and the Rotemberg model are equivalent to the first-order approximation. The main purpose of the paper is to compare the two models using a global nonlinear method. Hence it is crucial to make sure that they are the same to the first-order approximation. We set the parameters in the Taylor rule $\phi_{\pi}=1.5$ and $\phi_{y}=0.125$, as in Gali (2008) and Ascari and Rossi (2012), which are in the range of the empirical studies. The share of the government spending in output $S_{g}=0.20$, as in Christiano et al. (2011).

To reduce the number of state variables and ensure efficient numerical computations, we shut down the technology shock in all of our numerical solutions. We set the persistence of the preference shock and the government spending shock $\rho_{\beta}=\rho_{g}=0.8$, as in Adam and Billi (2007) and Fernandez-Villaverde et al. (2012). For robustness, we also consider many other values of the persistence of the government spending shock. Following Fernandez-Villaverde et al. (2012) we set the standard deviation of the innovation of government spending shocks 
$\sigma_{g}=0.25 \%$. We set the standard deviation of the innovation of preference shocks $\sigma_{\beta}=0.15 \%$ so that a $2 \%$ preference shock alone (i.e., the discount factor rises by $2 \%$ from 0.99 ) will make the ZLB binds for 5 periods as in Fernandez-Villaverde et al. (2012). This value is smaller than the value $0.25 \%$ used by Fernandez-Villaverde et al. (2012) because the inflation target in our paper is zero while it is $2 \%$ in their paper.

\section{Results}

\subsection{Policy functions}

The state variables for the Calvo model are $\Delta_{t-1}, \beta_{t}$, and $g_{t}$. By contrast, the relative price dispersion $\Delta_{t-1}$ does not appear in the Rotemberg model and its state variables are $\beta_{t}$ and $g_{t}$. We express equilibrium variables as policy functions of state variables.

Figure 1 shows policy functions for various positive values of the preference shock holding other state variables at their steady state levels. The solid lines represent the results from the Calvo model with the ZLB, while the dashed lines represent those from the Calvo model without the ZLB. ${ }^{5}$ The dot-dashed lines show the results from the Rotemberg model with the ZLB.

When there is a positive preference shock, households value their future consumption more, so they tend to save more and consume less today, putting downward pressure on output and the price level. To restore consumption and output, the real interest rate must fall. If the central bank were not restrained by the ZLB, it could adjust the nominal interest rate so that the actual real interest rate would be the same as the natural real rate.

However, because the ZLB is imposed, a big positive preference shock causes the ZLB to bind. As a result, the actual real interest rate will be larger than the natural real interest rate because the nominal interest rate cannot be negative. In general, the results from the Calvo and Rotemberg models have similar features to those in Adam and Billi (2007) and Ngo (2014). We summarize these features below.

First, in the absence of the ZLB, the central bank can stabilize the economy by adjusting the nominal interest rate using a simple Taylor rule in both the Calvo model and the Rotemberg model. But the government cannot obtain the target output and inflation as it could using optimal monetary policy.

Second, when the ZLB is present, the central bank cannot stabilize output and inflation under shocks that cause the ZLB to bind. As seen in Panels A and C of Figure 1, when the

\footnotetext{
${ }^{5}$ We use the nonlinear projection method to solve both the Calvo model and the Rotemberg model without the ZLB and find that the two models imply very similar results.
} 

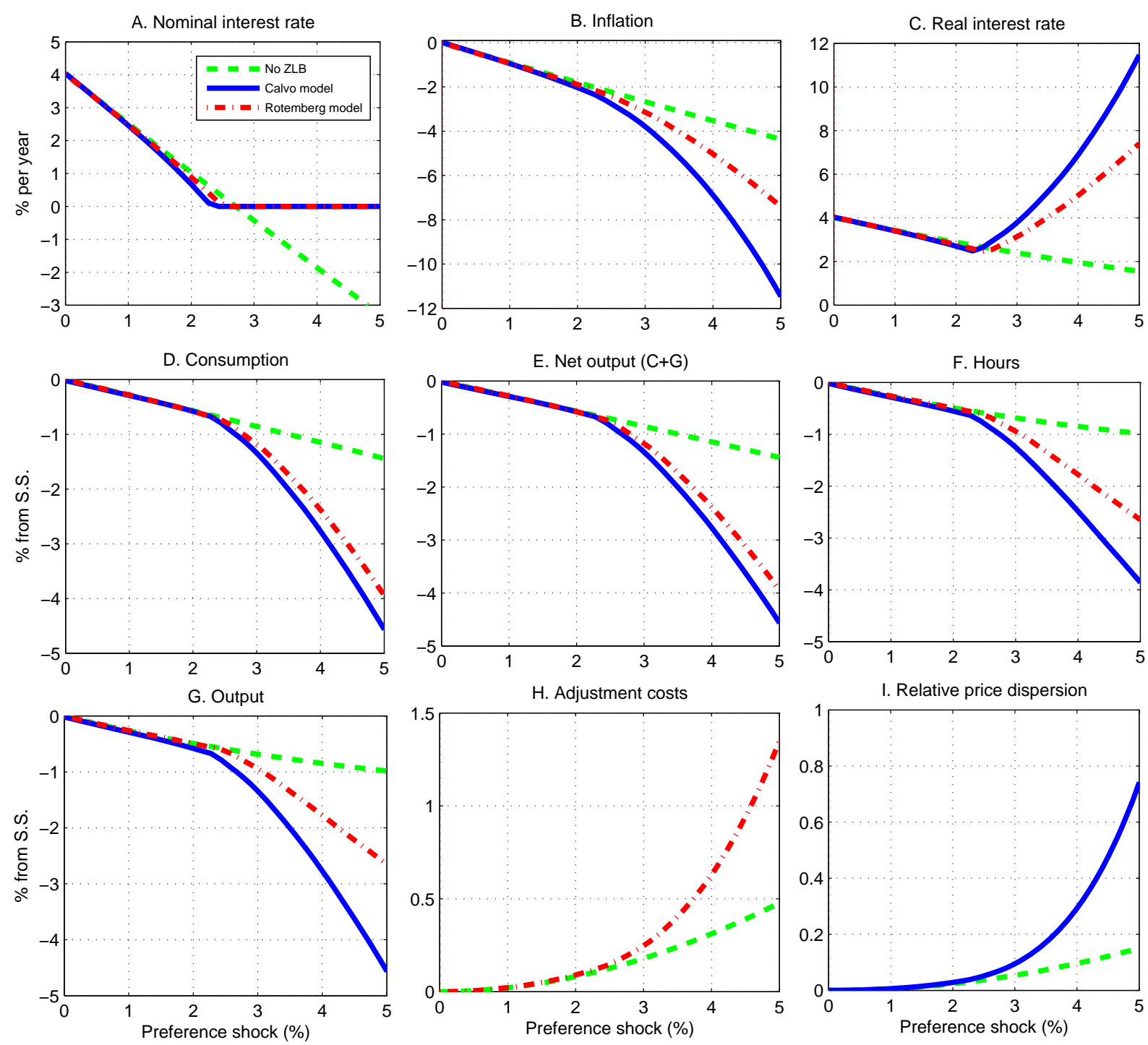

Figure 1: Policy functions when the relative price dispersion and the government spending shock are held at their steady-state levels $\left(\Delta_{t-1}=g_{t}=1\right)$. The preference shock is presented as an annualized percentage deviation from the steady state. Inflation rates and interest rates are annualized. 
nominal interest rate hits the ZLB, the real interest rate is higher than the natural real rate in both models, which is close to the real interest rate in the case without the ZLB. As a result, consumption, output, and hours worked fall substantially, as shown in Panels D, E, and F of Figure 1.

Third, the central bank cuts the nominal interest rate more aggressively, especially when the economy is near the ZLB, in the models with the ZLB than in the models without the ZLB. This aggressiveness occurs due to the risk of falling into the liquidity trap associated with deflation that forces the central bank to cut the interest rate more than it would without the risk. $^{6}$

Now let us turn our attention to analyzing the differences between the Calvo model and the Rotemberg model in the fully nonlinear framework. It is worth reminding the reader that the parameters in the two models are calibrated such that they generate the same results to a first-order approximation. In addition, the deterministic steady state is the same in the two models.

As Figure 1 shows, when the nominal interest rate is positive in the two models, these models generate very similar policy functions for consumption, net output (consumption plus government spending), hours worked, real marginal costs, and government spending. However, it is striking that the policy functions for the nominal interest rate, inflation, and the real interest rate are very different just before the ZLB binds. Specifically, the nominal interest rate cut is larger in the Calvo model than in the Rotemberg model given the same shock. Consequently, the ZLB is more likely to bind in the Calvo model than in the Rotemberg model. In other words, for the ZLB to bind, a smaller preference shock is sufficient in the Calvo model than in the Rotemberg model.

It is also interesting that, when the ZLB binds in the two models, the Calvo model generates a more severe recession. Given the same size of the preference shock that drives the ZLB to bind in the two models, the output loss and deflation are larger in the Calvo model than in the Rotemberg model, as seen in Panels G, B, and F of Figure 1. These results come from the fact that the real interest rate is much higher in the Calvo model than in the Rotemberg model (Panel C of Figure 1), leading to a higher incentive for households to save and a sharper decline in consumption and output in the Calvo model than in the Rotemberg model.

Why do the two models generate such different results in the fully nonlinear framework, especially when the ZLB binds? The answer lies in the adjustment costs as a part of aggregate demand (or waste of resources) in the Rotemberg model and the relative price dispersion variable

\footnotetext{
${ }^{6}$ See Adam and Billi (2007) and Ngo (2014) for more detailed explanation.
} 
as a negative technology shock in the Calvo model. The price dispersion variable equals one to a first-order approximation around the steady state with zero inflation, so it has no impact on the other variables regardless of the magnitude of shocks and inflation. In the Rotemberg model, the relative price dispersion is always equal to one because all firms charge the same price in a symmetric equilibrium and the adjustment costs are zero to a first-order approximation. This is the reason why the two models are equivalent to a first-order approximation.

However, this is not the case in the fully nonlinear framework. In this framework, while the relative price dispersion always equals one in the Rotemberg model, it is no longer one in the Calvo model. Under a large shock driving far away from the steady state, the relative price dispersion rises. Especially, when the ZLB binds and the central bank is unable to obtain the zero target inflation rate, the relative price dispersion is significantly greater than one (Panel I of Figure 1). In addition, the quadratic adjustment costs are large due to large deflation in the Rotemberg model (Panel $\mathrm{H}$ of Figure 1), mitigating the fall in consumption. These are the two main factors that cause the difference between the Calvo and Rotemberg models.

As discussed above, due to the roles of the relative price dispersion and price adjustment costs, we see a larger output decrease and higher deflation in the Calvo model than in the Rotemberg model. Thus the central bank in the Calvo model has a higher incentive to cut back the nominal interest rate to obtain the zero inflation target so that the relative price dispersion and price adjustment costs can be smaller. This implies that the probability for the nominal interest rate to hit the ZLB is larger in the Calvo model than in the Rotemberg model.

\subsection{Government spending multipliers}

The effectiveness of fiscal policy has received much attention recently from economists and policymakers when the target federal funds rate hits the ZLB and the conventional monetary policy is not effective in stimulating economic activities. Woodford (2011) argues that the government spending multiplier is possibly well in excess of one when monetary policy is constrained by the ZLB, especially in the case where government purchases expand to partially fill the output gap that arises from the inability to lower the nominal interest rate. Christiano et al. (2011) also show that the government expenditure multiplier is far above one when the economy is stuck in the liquidity trap with a binding ZLB.

In this section we compute and report government spending multipliers in two cases: when the economy is inside the ZLB and when it is outside the ZLB. 


\subsubsection{Multipliers when the ZLB is not binding}

To compute the multipliers when the economy is outside the ZLB, we first assume that initially in period 0 , the economy stays at the deterministic steady state. We then impose a $1 \%$ shock to the share of government spending $g_{t}$ in period 1 such that the government spending $G_{1}$ increases. $^{7}$ The share of government spending then returns to its steady-state level according to its law of motion. Using the approximate policy function, we compute and keep track the paths of output and government spending $\left(Y_{t}, G_{t}\right)_{t=0}^{T}$, where $T$ is big enough to make sure that the economy will converge to the steady state. We then compute the (impact) multiplier as $\left(Y_{1}-Y_{0}\right) /\left(G_{1}-G_{0}\right)$, where $G_{0}$ and $Y_{0}$ are the initial steady state levels of government spending and output.

Panel A of Figure 2 presents the multipliers for various levels of the government spending shock persistence $\rho_{g}$ when the economy is outside the ZLB. We find that the Calvo and Rotemberg models produce very similar government spending multipliers when the ZLB never binds. Under the benchmark parameterization where the persistence of the government spending shock is 0.8 , the multiplier is around 0.75 in both models. As explained above, in this case the central bank can obtain output and inflation close to the target. Therefore, the relative price dispersion is insignificantly different from one in the Calvo model and the adjustment costs in the Rotemberg model are close to zero.

Panel A of Figure 2 shows two notable results. First, the multiplier is always smaller than one in both models no matter how persistent the government spending shock is. This occurs because of the well-known crowding-out effect of government spending on private consumption. Specifically, an increase in government spending puts upward pressure on output and inflation. The central bank will raise the nominal interest rate through the Taylor rule such that the real interest increases to fight against higher inflation. Consequently, private consumption falls and hence the increase in output is smaller than the increase in government spending. This implies that the government spending multiplier is less than one.

Second, the multiplier decreases in the persistence of the government spending shock. The intuition is that, given the initial $1 \%$ increase in government spending, the more persistent the government spending shock, the longer the initial increase will last, and hence the larger inflation is in the future. Forward-looking firms will increase their current prices if they have a chance to do so, resulting in a larger current inflation. According to the Taylor rule, the central bank will raise the nominal interest rate and the real interest rate, leading to a larger crowding-out effect on private consumption. Thus the government multiplier is smaller as the

\footnotetext{
${ }^{7}$ The results in this case are quite robust to larger sizes of the government spending shock, such as $3 \%$ or $5 \%$.
} 


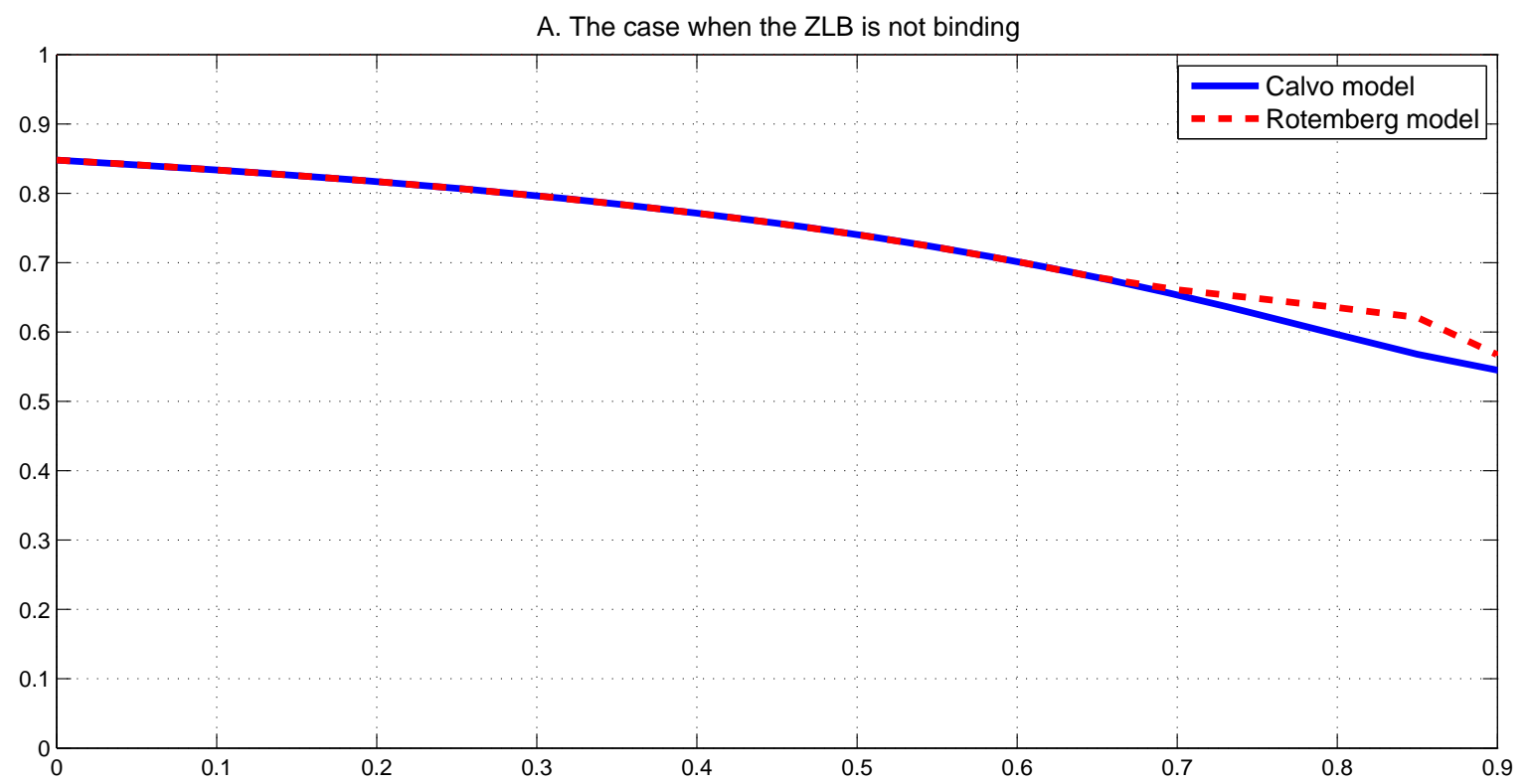

B. The case when the ZLB is binding

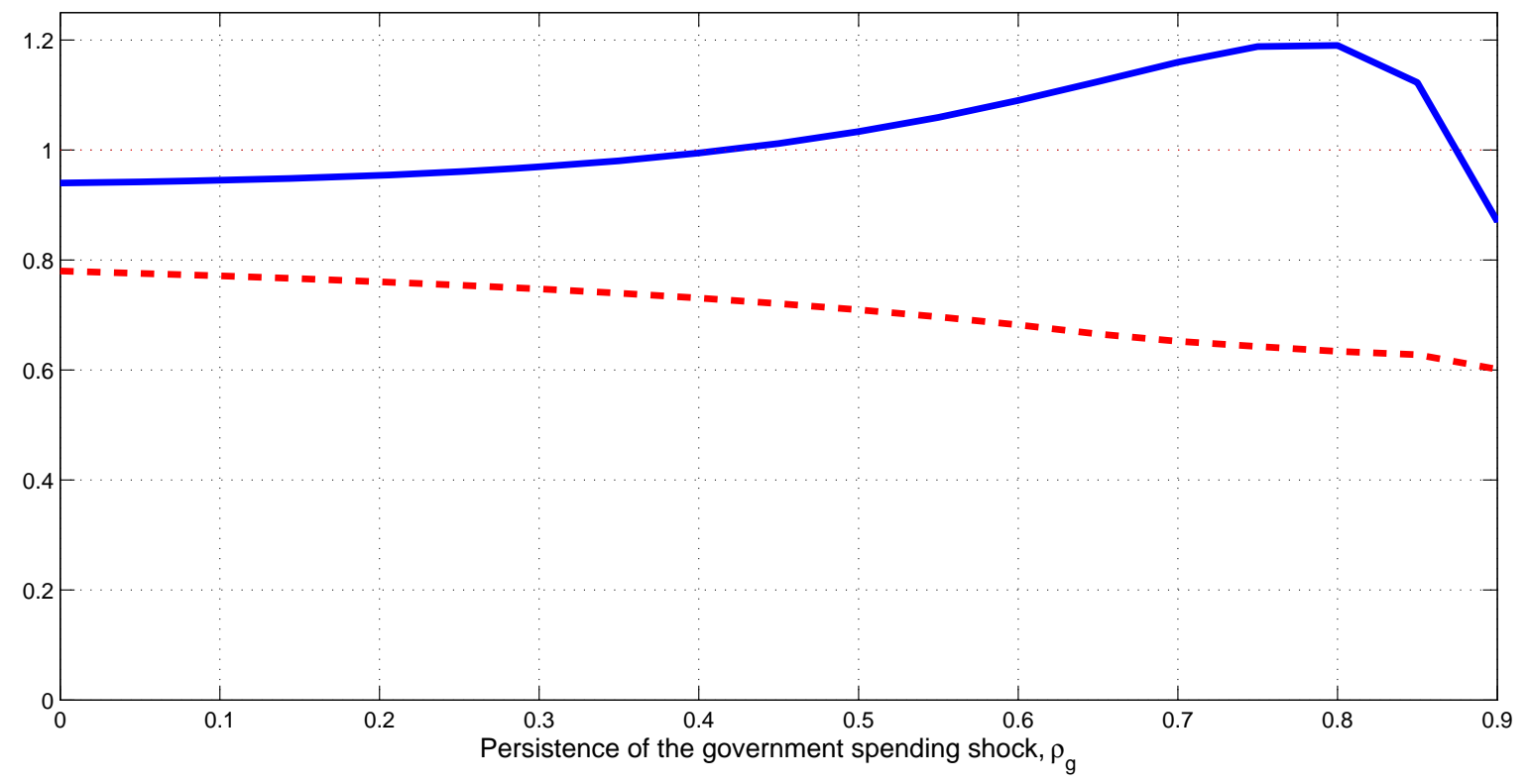

Figure 2: Government spending multipliers. The government spending shock is $1 \%$. There is no preference shock in the case where the ZLB is not binding, and the preference shock is $2 \%$ in the case where the ZLB is binding. 
persistence increases.

\subsubsection{Multipliers when the ZLB is binding}

This case is of particular interest because of the call for fiscal policy expansion during and after the Great Recession, where the target federal fund rate has been at the ZLB since December 2008. We use the following procedure to compute the multiplier when the economy is at the ZLB as in Fernandez-Villaverde et al. (2012).

First, we assume that the economy stays at the steady state initially in period 0 . We impose a $2 \%$ preference shock in period 1 such that, without any other shocks, the economy will stay at the ZLB for five periods. The preference shock returns to the steady state according to its law of motion in period $T$. We compute and keep track of the paths of output and government spending under the preference shock only, $\left(Y_{t}^{1}, G_{t}^{1}\right)_{t=0}^{T}$.

Second, on top of the preference shock, we impose a $1 \%$ shock to the share of government spending $g_{t}$ in period 1 such that the government spending $G_{1}$ in period 1 increases. Both the preference and government spending shocks then return to the steady state according to their laws of motion in period $T$. We compute and keep track of the paths of output and government spending under the two shocks, $\left(Y_{t}^{2}, G_{t}^{2}\right)_{t=0}^{T}$. The number of periods for the exercise, $T$, is large enough to make sure that the economy will converge to the deterministic steady state. We compute the (impact) multiplier as $\left(Y_{1}^{2}-Y_{1}^{1}\right) /\left(G_{1}^{2}-G_{1}^{1}\right)$. Figure 3 presents the results for various levels of persistence $\rho_{g}$.

Under the benchmark calibration where $\rho_{g}=0.8$, the multiplier is around 1.18 in the Calvo model, while it is around 0.65 in the Rotemberg model. These values are much smaller than those reported in the existing literature. Woodford (2011) and Christiano et al. (2011) find that the impact multiplier is around 2 in their benchmark model with Calvo pricing. One reason for the difference in results is that they use log-linear solution methods, while we use global nonlinear solution methods. The other reason is that they use a two-state Markov shock to push the economy to the ZLB as in Eggertsson and Woodford (2003), while we use an AR(1) process for the discount factor shock. The exogenously fixed probability of staying in the ZLB is large in their model. For example, that probability is calibrated to be 0.903 in Woodford's paper. Hence, the ZLB in his model binds approximately 10 quarters on average instead of 5 quarters as in this paper. We will investigate how the duration of the ZLB affects the multipliers in the next section.

Panel B of Figure 2 shows that the Calvo and Rotemberg models produce very different government spending multipliers on impact. First, while the multiplier is always smaller than one 
in the Rotemberg model regardless of the magnitude of the government spending persistence, it can be larger than one in the Calvo model. Second, the multiplier in the Calvo model first increases then decreases in the persistence, while it generally decreases with the persistence in the Rotemberg model. Third, the multiplier is always greater in the Calvo model than in the Rotemberg model.

The less-than-one impact multiplier in the Rotemberg model, which is robust to the persistence of the government spending shock, is surprising because there is a conventional belief that when the ZLB binds, the government spending multiplier is greater than one in a DNK model with sticky prices, as discussed in Christiano et al. (2011), Woodford (2011), Eggertsson and Krugman (2012), among others.

To understand the intuition, Figure 3 plots impulse responses of some key economic variables to a $1 \%$ shock to government spending for the Rotemberg model in which there is a $2 \%$ preference shock that makes the ZLB binds for 5 periods. This figure shows that the government spending shock is so small that the economy does not escape from the ZLB for 5 periods. But it raises inflation (actually reduces deflation). Thus the real interest rate falls until period 5 , causing consumption to rise. The net output $\left(C_{t}+G_{t}\right)$ then rises more than one percent, but total output $Y_{t}=C_{t}+G_{t}+\varphi \pi_{t}^{2} Y_{t} / 2$ does not. The key reason is that the adjustment costs $\varphi \pi_{t}^{2} Y_{t} / 2$ fall due to the fall in deflation.

Figure 3 also plots the case for $\rho_{g}=0$ and $\rho_{g}=0.8$. Because the government spending shock is purely temporary when $\rho_{g}=0$, the inflation rate rises (deflation reduces) on impact and then returns to the level without the shock in the second period. Since the real interest rate is approximately equal to the nominal interest rate minus the expected inflation rate $\left(r_{t}=i_{t}-E_{t} \pi_{t+1}\right)$, the real interest rate does not change. As a result, consumption does not change. Since deflation is reduced on impact, the adjustment costs fall on impact, but the magnitude is smaller than that for $\rho_{g}=0.8$. Thus, the multiplier for $\rho_{g}=0$ is less than one, but higher than that for $\rho_{g}=0.8$.

When $\rho_{g}=0.9$, the government spending shock is almost permanent. Because households must pay lump-sum taxes to finance government spending, there is a negative wealth effect. This effect dominates the positive substitution effect due to the fall in the real interest rate so that consumption falls on impact when $\rho_{g}=0.9$. Even though the inflation rate rises less and the adjustment costs fall less than the case of $\rho_{g}=0.8$, total output rises less on impact. Thus the government spending multiplier when $\rho_{g}=0.9$ is smaller than when $\rho_{g}=0.8$. Note that this smaller multiplier is not due to the common view that a highly persistent government spending shock can cause the economy to escape from the ZLB. In our model the ZLB still 

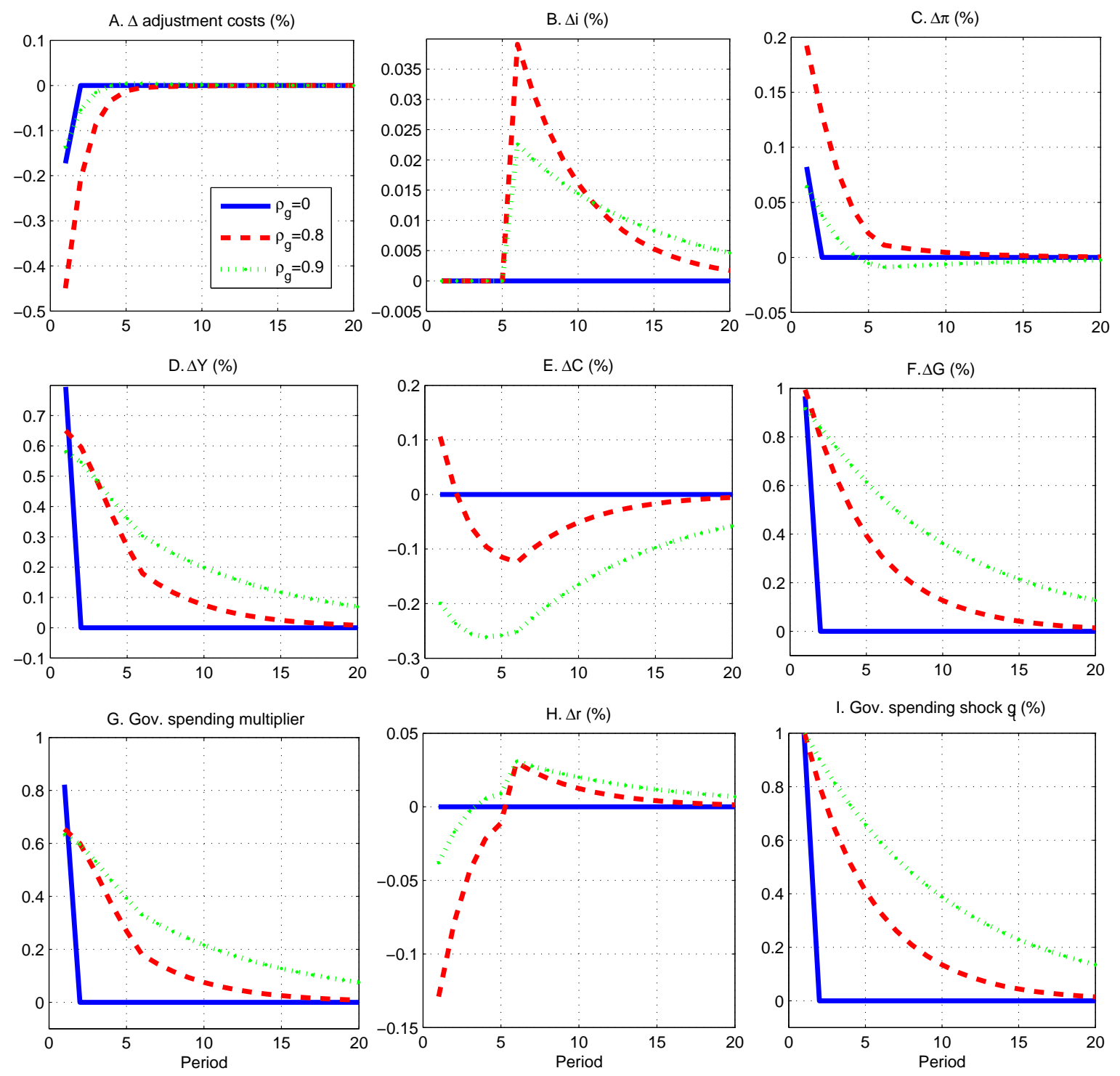

Figure 3: Impulse responses to a $1 \%$ government spending shock for the Rotemberg model in which there is a $2 \%$ preference shock that makes the ZLB bind for 5 periods. For interest rates and inflation rates, we present level differences, but for quantities we present differences relative to the deterministic steady state. For example, $\Delta i_{t}=i_{t}^{2}-i_{t}^{1}$ and $\Delta Y_{t}=\left(Y_{t}^{2}-Y_{t}^{1}\right) / Y * 100$, where the supercript 2 (1) means the economy with two (one) shocks. Inflation rates and interest rates are annualized. 
binds for 5 periods when $\rho_{g}=0.9$.

It is surprising to note from Figure 2 that the multiplier in the Rotemberg model is smaller when the ZLB binds than when the ZLB does not bind for sufficiently small $\rho_{g}$, contrary to the conventional view that the binding ZLB would raise the multiplier. To understand the intuition, consider the extreme case of $\rho_{g}=0$. As analyzed above, consumption does not change from the level with the preference shock alone when the ZLB binds because inflation rises only on impact and then immediately returns to the level with the preference shock alone. But price adjustment costs fall on impact due to smaller deflation, generating a multiplier of 0.78 . When the ZLB does not bind, consumption falls on impact due to the crowding-out effect analyzed earlier and inflation rises on impact, causing the price adjustment costs to rise and mitigate the fall of consumption. This effect can dominate so that the multiplier in the Rotemberg model when the ZLB does not bind (0.85) is larger than that when the ZLB binds (0.78).

Why is the multiplier much larger in the Calvo model than in the Rotemberg model when the ZLB is binding? As explained in Section 4.1 for the case without a government spending shock, the relative price dispersion can be significantly greater than its steady-state level of one in the Calvo model if the ZLB binds, while the dispersion is always equal to one in the Rotemberg model. Now there are two effects in the Calvo model when the government spending rises. First, as in the Rotemberg model, government spending generates inflation (smaller deflation) directly, leading to a lower real interest rate given the nominal interest rate stuck at the ZLB, resulting in higher output and inflation that are close to the target. The closer the inflation to the target, the smaller the relative price dispersion, leading to a smaller output loss and an inflation rate closer to the target. Therefore, the impact of government spending is much stronger in the Calvo model than in the Rotemberg model due to the effect of the relative price dispersion. Like Figure 3, Figure 4 illustrates the preceding intuition.

Why is the multiplier not monotonic in the persistence of the government spending shock in the Calvo model? When the persistence of the government spending shock increases, higher future inflation is created, leading to a higher current inflation rate and hence a smaller real interest rate as long as the ZLB binds. That is why the multiplier first increases in the persistence of the government spending shock. However, if the shock is too persistent, the negative wealth effect dominates the positive substitution effect so that consumption falls on impact. Therefore, the multiplier starts decreasing when the persistence is sufficiently high.

Figure 4 illustrates the intuition by comparing impulse responses for $\rho_{g}=0,0.8$, and 0.9 in the Calvo model. When $\rho_{g}=0$, in response to a $1 \%$ shock to government spending, inflation rises on impact, but falls in the second period and then returns to the level without the shock. 

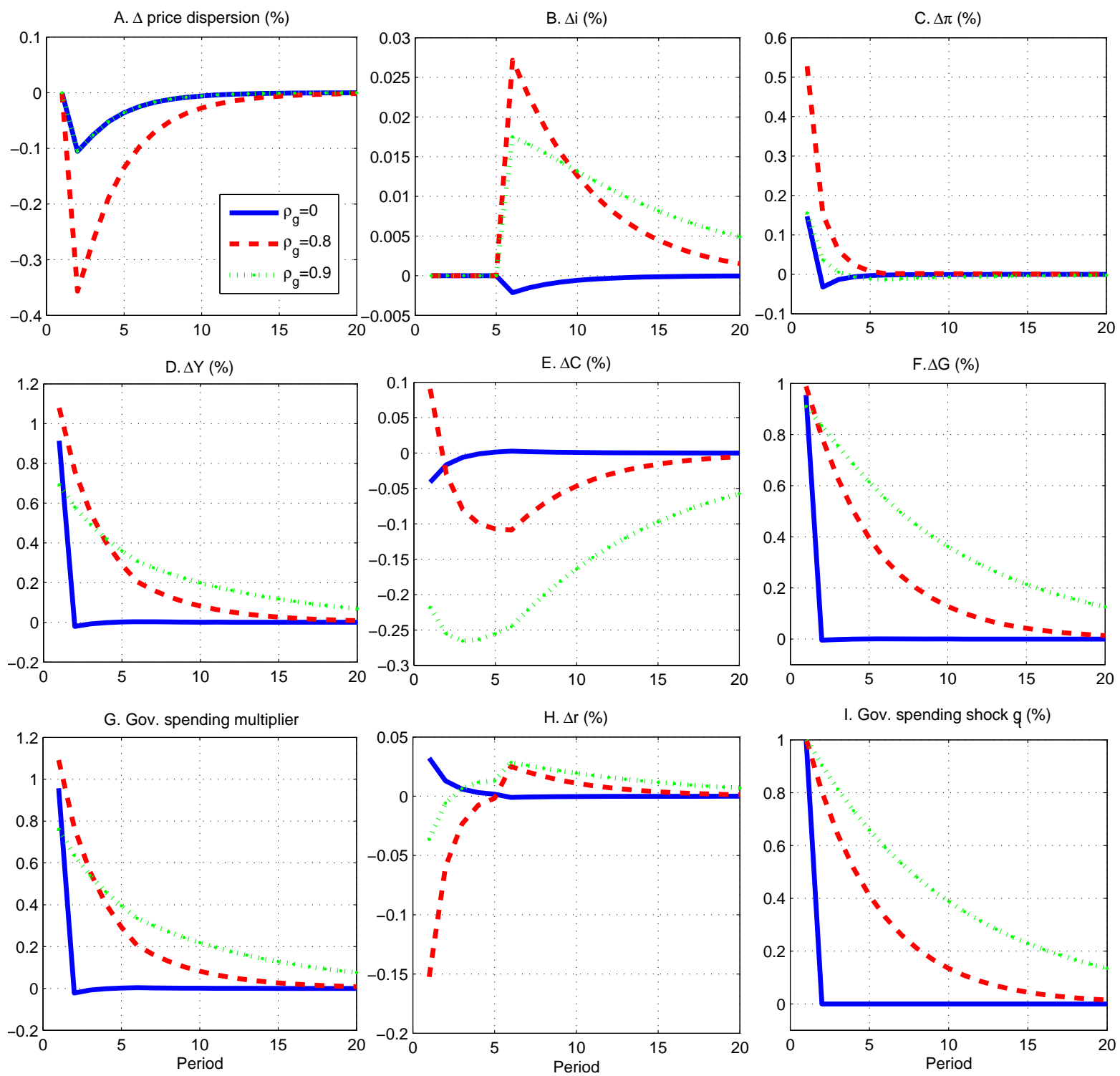

Figure 4: Impulse responses to a $1 \%$ government spending shock for the Calvo model in which there is a $2 \%$ preference shock that makes the ZLB bind for 5 periods. For interest rates and inflation rates, we present level differences, but for quantities we present differences relative to the deterministic steady state. For example, $\Delta i_{t}=i_{t}^{2}-i_{t}^{1}$ and $\Delta Y_{t}=\left(Y_{t}^{2}-Y_{t}^{1}\right) / Y * 100$, where the supercript 2 (1) means the economy with two (one) shocks. Inflation rates and interest rates are annualized. 
This is because the relative price dispersion is a state variable in the Calvo model. It falls on impact and gradually rises to the level associated with the preference shock only. The fall in the price dispersion acts as a positive technology shock, which raises aggregate supply. Thus there is deflation in the second period so that the real interest rate rises on impact for $\rho_{g}=0$. This causes consumption to fall so that the government spending multiplier is less than one when $\rho_{g}=0$. As $\rho_{g}$ increases, the multiplier gradually rises and exceeds one for $\rho_{g}=0.8$. But when $\rho_{g}=0.9$, the negative wealth effect causes consumption to fall so that the multiplier is less than one.

\section{$5 \quad$ Sensitivity analysis}

To examine the robustness of our results, we conduct several sensitivity analyses in this section.

\subsection{Taylor rule parameters}

The parameters in the Taylor rule may change over time (e.g., Judd and Rudebusch (1998), Clarida et al. (2000), and Sims and Zha (2006)). We now study the impact of changes in the parameters $\phi_{\pi}$ and $\phi_{y}$. Figure 5 shows that the multiplier increases with $\phi_{\pi}$ for the Rotemberg model, but it is non-monotonic for the Calvo model for various levels of the persistence of the government spending shock. The intuition is the following. When $\phi_{\pi}$ is larger, the central bank responds to the inflation gap more aggressively. Thus the ZLB is more likely to bind so that the duration of the binding ZLB is longer. This effect raises the government spending multiplier. But there is another negative wealth effect when the persistence of the government spending shock is larger. As discussed earlier, this effect may dominate causing the multiplier non-monotonic with the persistent parameter in the Calvo model. Similarly, this can cause the impact of $\phi_{\pi}$ and $\phi_{y}$ on the multiplier non-monotonic in the Calvo model. But the impact in the Rotemberg model is monotonic.

\subsection{Duration of the ZLB}

How does the duration of being at the ZLB affect the multipliers? Using DNK models with Calvo pricing, both Woodford (2011) and Christiano et al. (2011) find that the longer the economy stays at the ZLB, the larger the government spending multiplier.

To revisit this issue, we first impose three levels of the preference shock $(1 \%, 2 \%$, and $3 \%)$ such that the economy will stay at the ZLB for 2, 5, 6 periods in the Calvo model and for 2, 5 , and 7 periods in the Rotemberg model. We then impose a $1 \%$ government spending shock on top of the preference shock and compute the impact multiplier. This shock is so small that 
A. A sensitivity analysis with different values of $\phi_{\pi}$

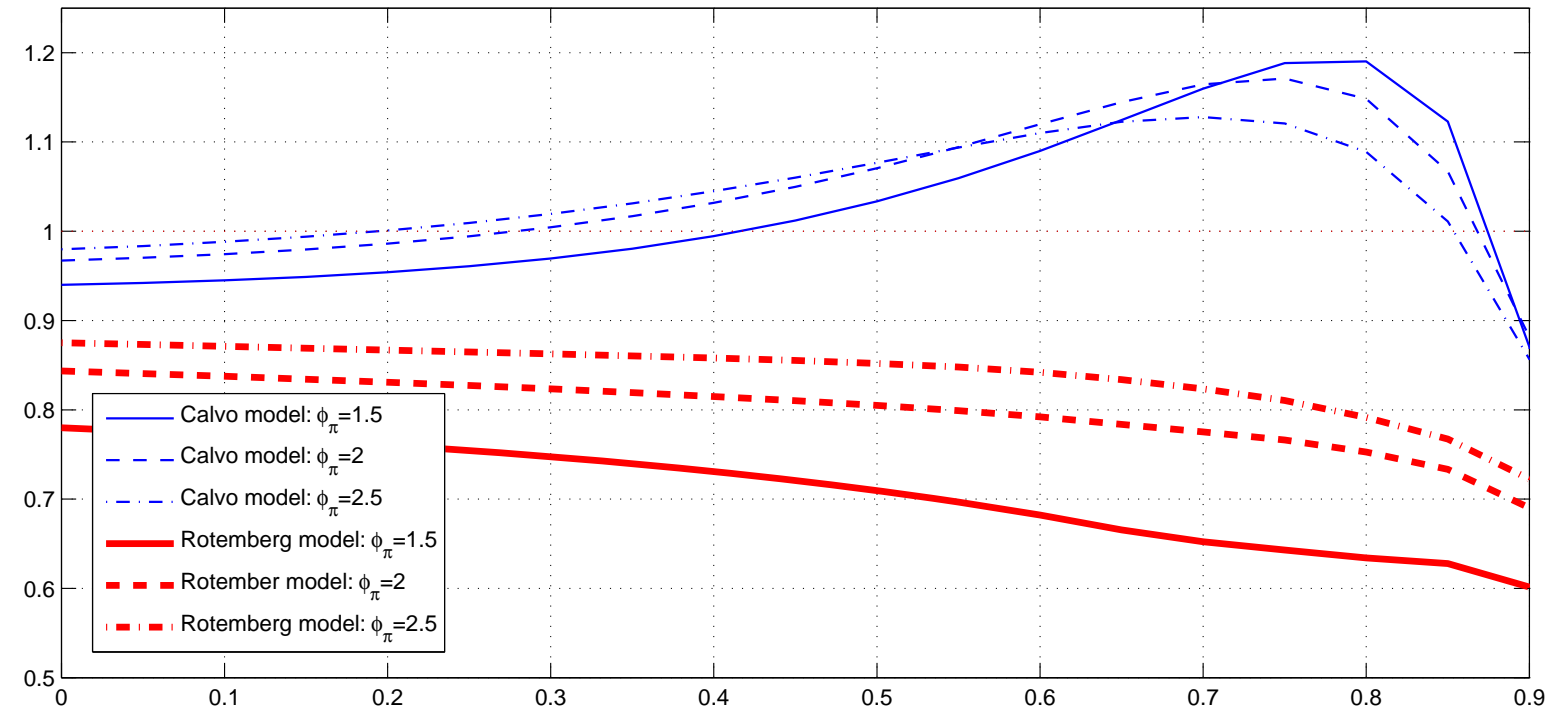

B. A sensitivity analysis with different values of $\phi_{y}$

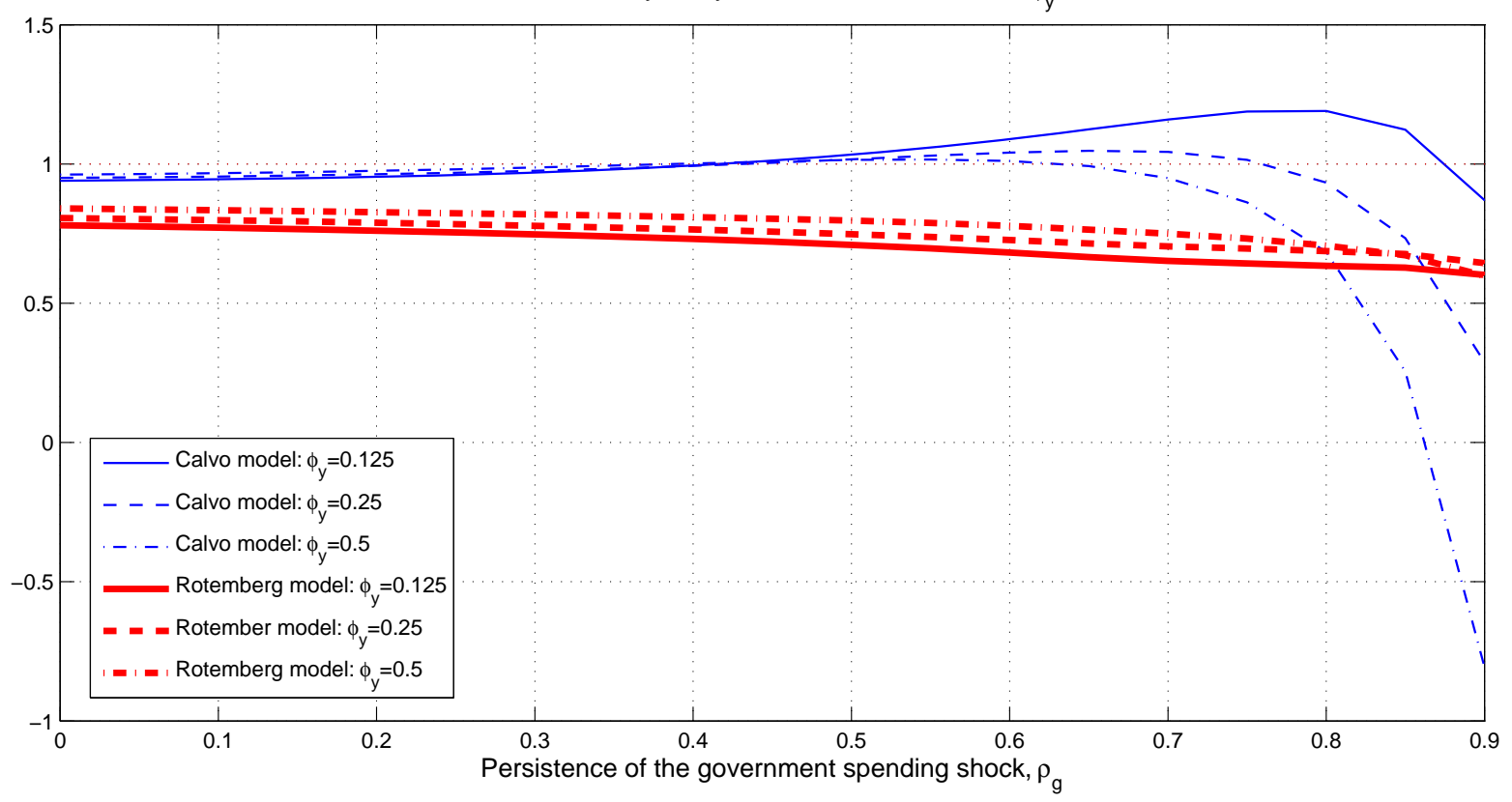

Figure 5: Impact of $\phi_{\pi}$ and $\phi_{y}$ on the government spending multiplier. The government spending shock is $1 \%$ and the preference shock is $2 \%$. 
Table 2: The impact of duration on the multiplier

\begin{tabular}{l|lll|lll}
\hline & \multicolumn{3}{|l|}{ Calvo model } & \multicolumn{3}{l}{ Rotemberg } \\
\hline Preference shock & $1 \%$ & $2 \%$ & $3 \%$ & $1 \%$ & $2 \%$ & $3 \%$ \\
Duration & 2 & 5 & 6 & 2 & 5 & 7 \\
Multiplier & 0.82 & 1.18 & 1.23 & 0.75 & 0.65 & 0.31 \\
Change of consumption (\%) & -0.18 & 0.09 & 0.12 & -0.19 & 0.11 & 0.28 \\
Change of adj. costs (\%) & - & - & - & -0.06 & -0.45 & -0.93 \\
\hline
\end{tabular}

Note: The changes of consumption and adjustment costs are computed for the initial period and normalized by the steady state output.

the economy will not escape from the ZLB. The results are presented in Table 2. We find that the multiplier increases with the duration in the Calvo model and it is less than one when the duration of the ZLB is two for the $1 \%$ preference shock. The reason is that the positive substitution effect due to the drop in the real interest rate is dominated by the negative wealth effect.

By contrast, the multiplier for the Rotemberg model is always less than one and decreases with the duration of the ZLB. Although consumption rises when the duration is longer, adjustment costs fall more because of smaller deflation.

\subsection{Adjustment costs with rebate}

So far we have assumed that the Rotemberg adjustment cost represents a pure waste for the economy and goes into the resource constraint. This is the most common assumption in the DNK literature. To understand the robustness of our results on the difference between the Rotemberg and Calvo models, we consider the case in which the adjustment costs are rebated to consumers. In this case the aggregate resource constraint becomes $C_{t}+G_{t}=Y_{t}$. Then the multiplier in the Rotemberg model with rebate exceeds one and is larger than that in the Calvo model as illustrated in Figure 6. The smaller multiplier in the Calvo model is due to the negative impact of the price dispersion. Note that the impact of persistence on the multiplier in the Rotemberg model with rebate is also non-monotonic because of the negative wealth effect. But the rebate of adjustment costs mitigates the negative wealth effect so that it is not large enough to cause consumption to fall on impact. 


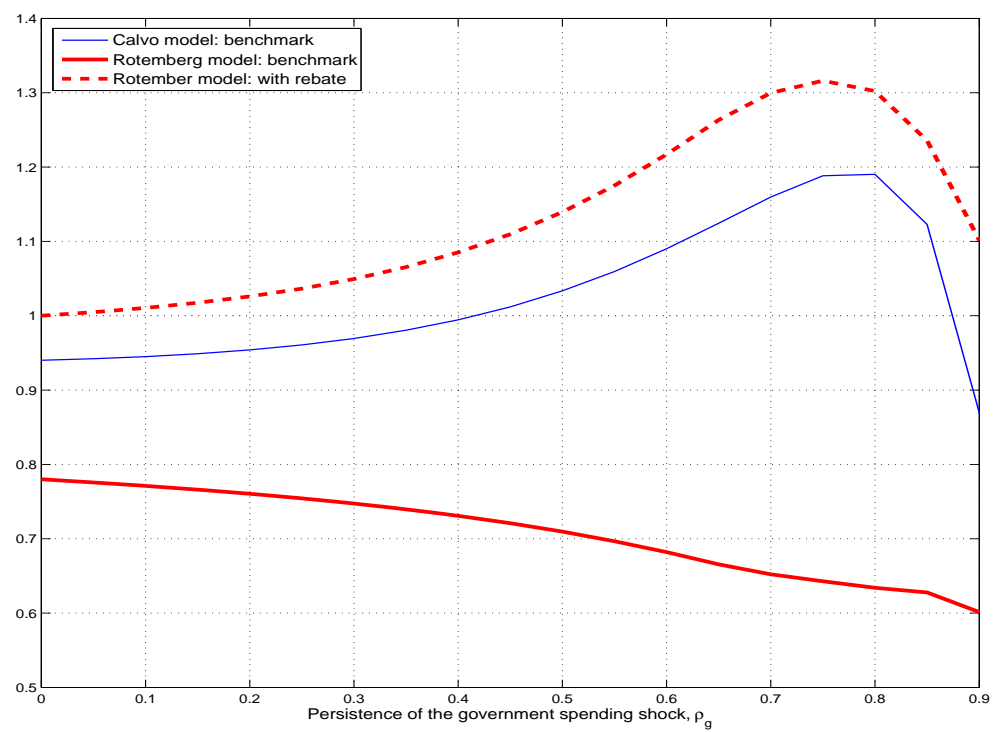

Figure 6: Impact government spending multipliers when the ZLB is binding due to an adverse preference shock. The government spending shock is $1 \%$, and the preference shock is $2 \%$ when the ZLB binds.

\section{Conclusion}

This paper explores the differences between the Calvo model and the Rotemberg model in a fully nonlinear DNK framework with an occasionally binding ZLB on nominal interest rates. We find that the magnitude of the government spending multiplier can be less than one and depends crucially on the modeling of the price setting mechanism, the persistence of the government spending shock, and the duration of the ZLB. The main reason is that the relative price dispersion is a state variable in the Calvo model and acts as a negative technology shock, while the quadratic price adjustment costs in the Rotemberg model are a part of aggregate demand or a waste of resources. Moreover, the persistence of the government spending shock affects the relative strength of the substitution and wealth effects on consumption.

Our findings challenge the widely held belief that DNK models with sticky prices generally produce a greater-than-one government spending multiplier when the ZLB binds and the multiplier increases with the duration of the ZLB. In future research, it would be interesting to see how large the government spending multiplier will be in the class of state-dependentpricing DNK models such as Dotsey et al. (1999), Golosov and Lucas (2007), and Gertler and Leahy (2008). These models can match the micro-level price data better than the Calvo and Rotemberg models considered in this paper. Investigating the effect of monetary and fiscal 
policy under the ZLB constraint in the state-dependent pricing framework is part of our future research agenda. 


\section{References}

Adam, K. and M. Billi (2006). Optimal monetary policy under commitment with a zero bound on nominal interest rates. Journal of Money, Credit, and Banking 38(3), 1877-1905.

Adam, K. and M. Billi (2007). Discretionary monetary policy and the zero lower bound on nominal interest rates. Journal of Monetary Economics 54, 728-752.

Aruoba, B. and F. Shorfheide (2013). Macroeconomic dynamics near the zlb: A tale of two equilibria. NBER Working Paper.

Ascari, G. and L. Rossi (2012). Trend inflation and firms price-setting: Rotemberg versus calvo. The Economic Journal 122.

Benhabib, J., S. Schmitt-Grohe, and M. Uribe (2001). The perils of taylor rules. Journal of Economic Theory 96, 40-69.

Benhabib, J., S. Schmitt-Grohe, and M. Uribe (2002). Avoiding liquidity traps. Journal of Political Economy 110, 535-563.

Braun, R. A., M. L. Korber, and Y. Waki (2013). Small and orthodox fiscal multipliers at the zero lower bound. Federal Reserve Bank of Atlanta Working Paper.

Braun, R. A. and Y. Waki (2010). On the size of the fiscal multiplier when the nominal interest rate is zero. Federal Reserve Bank of Atlanta Working Paper.

Calvo, A. (1983). Staggered prices in a utility maximizing framework. Journal of Monetary Economics 12, 383-398.

Christiano, L., M. Eichenbaum, and S. Rebelo (2011). When is the government spending multiplier is large? Journal of Political Economy 113, 1-45.

Clarida, R., J. Gali, and M. Gertler (2000). Monetary policy rules and macroeconomic stability: Evidence and some theory. Quarterly Journal of Economics 115, 147-180.

Diewert, E. and K. Fox (2008). On the estimation of return to scale, technical progress and monopolistic markups. Journal of Econometrics 145, 174-193.

Dotsey, M., R. G. King, and A. L. Wolman (1999). State-dependent pricing and the general equilibrium dynamics of money and output. Quarterly Journal of Economics 114, 655-690.

Eggertsson, G. (2011). What fiscal policy is effective at zero interest rates. $2010 \mathrm{NBER}$ Macroeconomics Annual, 59 - 112.

Eggertsson, G. and P. Krugman (2012). Debt, deleveraging and the liquidity trap: A fisher minsky - koo approach. Quarterly Journal of Economics 127(3), 1469-1513.

Eggertsson, G. and M. Woodford (2003). The zero bound on interest rates and optimal monetary policy. NBER Working Paper. 
Fernandez-Villaverde, J., G. Gordon, P. Guerron-Quintana, and F. J. Rubio-Ramirez (2012). Nonlinear adventures at the zero lower bound. NBER Working Paper.

Gali, J. (2008). Monetary Policy, Inflation, and the Business Cycle: An Introduction to the New Keynesian Framework. Princeton University Press.

Gertler, M. and J. Leahy (2008). A phillips curve with an ss foundation. Journal of Political Economy 116(3), 533-572.

Golosov, M. and R. E. Lucas (2007). Menu costs and phillips curves. Journal of Political Economy 115(April), 171-199.

Gust, C., D. Lopez-Salido, and M. Smith (2012). The emperical implications of the interest-rate lower bound. Federal Reserve Board Manuscript.

Judd, J. and D. G. Rudebusch (1998). Taylor's rule and the fed: 1970 - 1997. Federal Reserve Bank of San Francisco Economic Review 3, 3-16.

Judd, K. L. (1998). Numerical Methods in Economics. MIT Press.

Judd, L. K., L. Maliar, and S. Maliar (2011). A cluster-grid algorithm: Solving problems with high dimensionality. Working Paper.

Krugman, P. (1998). It's baaack: Japan's slump and the return of the liquidity trap. Brookings Papers on Economic Activity 2, 137-205.

Mertens, K. and O. M. Ravn (2014). Fiscal policy in an expectations driven liquidity trap. Working Paper.

Miao, J. (2014). Economic Dynamics in Discrete Time. MIT Press.

Miranda, M. J. and L. P. Fackler (2002). Applied Computational Economics and Finance. MIT Press.

Nakamura, G. and J. Steinsson (2008). Five facts about prices: A reevaluation of menu cost models. Quarterly Journal of Economics 123(4), 1415-1464.

Ngo, P. (2014). Optimal discretionary monetary policy in a micro-founded model with a zero lower bound on nominal interest rate. Journal of Economic Dynamics and Control 45, 44-65.

Rotemberg, J. (1982). Sticky prices in the united states. Journal of Political Economy 90, $1187-211$.

Sims, A. C. and T. Zha (2006). Were there regime switches in u.s. monetary policy? The American Economic Review 96 (1), 54-81.

Woodford, M. (2003). Interest and Prices: Foundations of a Theory of Monetary Policy. Princeton University Press.

Woodford, M. (2011). Simple analytics of the government expenditure multipliers. American Economic Journal: Journal of Macroeconomics 3, 1-35. 